\title{
Process chains for the mass production of transparent crowns for posterior teeth
}

Islam, Aminul; Hansen, Hans Nørgaard; Rabenow, Lisa; Nielsen, Keld

Published in:

CIRP annals

Link to article, DOI:

10.1016/j.cirp.2019.04.015

Publication date:

2019

Document Version

Peer reviewed version

Link back to DTU Orbit

Citation (APA):

Islam, A., Hansen, H. N., Rabenow, L., \& Nielsen, K. (2019). Process chains for the mass production of transparent crowns for posterior teeth. CIRP annals, 68(1), 591-594. https://doi.org/10.1016/j.cirp.2019.04.015

\section{General rights}

Copyright and moral rights for the publications made accessible in the public portal are retained by the authors and/or other copyright owners and it is a condition of accessing publications that users recognise and abide by the legal requirements associated with these rights.

- Users may download and print one copy of any publication from the public portal for the purpose of private study or research.

- You may not further distribute the material or use it for any profit-making activity or commercial gain

- You may freely distribute the URL identifying the publication in the public portal

If you believe that this document breaches copyright please contact us providing details, and we will remove access to the work immediately and investigate your claim 


\title{
Process chains for the mass production of transparent crowns for posterior teeth
}

\author{
Aminul Islam a, b, , Hans Nørgaard Hansen (1) ${ }^{b}$, Lisa Rabenow c, Keld Nielsen d \\ a Centre for Acoustic-Mechanical Micro Systems, Technical University of Denmark \\ ${ }^{b}$ Department of Mechanical Engineering, Technical University of Denmark \\ ${ }^{c}$ GEA Process Engineering A/S Denmark \\ ${ }^{d}$ Dentawi ApS, Denmark
}

This paper presents the work associated with the development of an innovative crown for posterior teeth. The idea is to produce a transparent cap that is mounted on top of the tooth, in this way facilitating the gluing of the crown and ensuring a good visual compatibility with the existing tooth. For the proposed crown concept, two properties are especially important - surface roughness and transparency. The paper presents the development and evaluation of two process chains based on industrially adaptive production methods. The process chains are compared based on their ability to meet product specifications in terms of roughness, transparency and mechanical properties.

Surface roughness optimization, Processing, Transparency

\section{Introduction and motivation}

The paper presents the possibility of industrial mass production of posterior teeth (molar and premolar teeth shown in Fig 1-A). A dental crown is a cap-like restoration used to cover a damaged tooth (shown in Fig 1-B). Crowns are used when a tooth is badly decayed, broken, fractured, or needs a cosmetic makeover. The dentists use a broad range of materials for crowns adopting newer materials into practices as they become available [1]. The commonly used materials for crowns are metals, ceramics, and composites. Even after the significant technological developments in the crown technology, crowns with transparent materials have never been reported. The idea is novel and offers many advantages. Matching the color of a crown to natural dentition is often a clinical challenge [2]. In the current work, this challenge is overcome with the innovative idea of a transparent crown. As the crown is transparent, it will be possible to harden the filler (the dental glue/cement) by an optical method. The required light to cure the filler will penetrate through the crown and harden the filler to bind the crown with the base of the tooth.

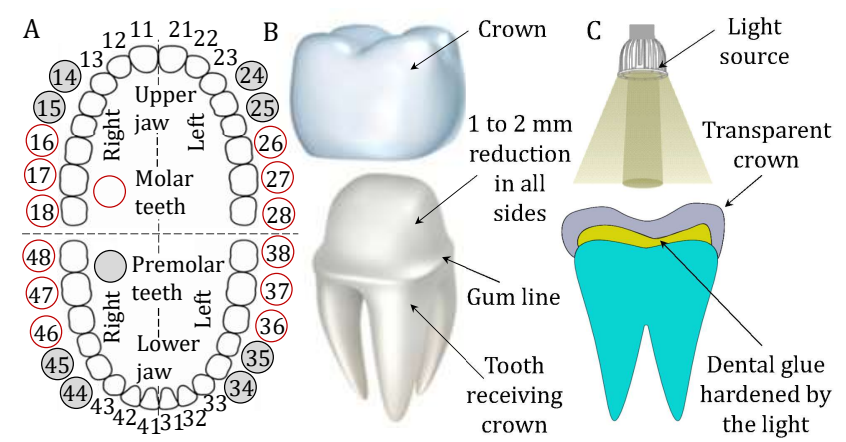

Figure 1. The standard teeth numbering showing molar and pre-molar teeth (A), a schematic representation of a traditional crown and the tooth prepared to receive the crown (B), the new crown mounting concept with the use of transparent crown (C).

The mounting concept of the new idea is schematically presented in Fig 1-C. The color of the hardened filler will be visible through the transparent crown. In this way, the crown color will be changed by controlling the color of the filler which is much easier and simpler compared to change the color of the crown. Traditional crowns are custom-made and typically involve a range of time-consuming tasks. The new crown concept is suitable for industrial mass production, can be produced in different size groups (such as small, medium and large) to fit the whole range of the population. State-of-the-art crowns entirely cap the tooth from the gum line (see Fig 1-B), which is not necessary for the newly designed crown, meaning that the new crown can be placed with a minimal removal of the original tooth.

For the successful production of the crown, a rigorous quality control is necessary to ensure the requirements in terms of strength, stiffness, hardness, surface roughness, and color. For the proposed crown concept, two properties are especially important: i) the surface roughness; and ii) the optical transparency of the crown. The surfaces of objects destined to be part of the human body (e.g. dental crowns, implants, prostheses, etc.) are the primary place of contact between the material and its host organism [3]. Two critical issues with the long-term use of such surfaces are bacterial colonization and wear [3]. The rough surface for a dental crown can provide cavities where the bacteria can thrive and impose difficulties to clean the tooth. Another issue with the surface roughness is the wear of the neighboring teeth, which come in contact with the crown during chewing. Last but not least, the surface roughness is important in relation to the transparency of the material. The high surface roughness can be responsible for a high scattering of the light resulting in a low transparency [4]. Obtaining the required surface roughness and transparency together with the right mechanical properties for the newly proposed crown idea is an industrial challenge. The production and process feasibilities of the new crown were realized by a series of experiments. The final production process was optimized to achieve the required surface roughness and transparency of the crown. The results discussed in the paper provide new insights for the glass and ceramic material processing along with the guidelines for the optimization of the surface roughness and optical transparency.

\section{Technical requirements, material, and process selection}

Even though crowns are extensively made and used, it is difficult to find general technical requirements for the crowns. The authors made an extensive literature review and consulted with several dentists. Based on these, the requirements for molar and pre-molar crowns established are: i) Withstand temperature from min $-15{ }^{\circ} \mathrm{C}$ to $100{ }^{\circ} \mathrm{C}$, ii) Hardness of 5 on Mohs scale (approximately 550 in Vickers hardness-HV), iii) Young's modulus of minimum $50 \mathrm{GPa}$, iv) Compressive strength of minimum $90 \mathrm{MPa}$, vi) Roughness ( $\mathrm{S}_{\mathrm{a}}$ ) below $500 \mathrm{~nm}$. Moreover, the material has to be optically transparent. Transparent materials become more and more important for applications in which materials are subject to extremely high mechanical and thermal stresses. Such as, transparent armour materials for military and civil applications, advanced optoelectronic devices, optical fibers, laser interferometers, solar cells, protective optics, etc. [5]. In the field of optics, transparency is the physical property of the material that allows light to pass through the material without being scattered. The transparency can be 
affected by many properties, including the part thickness, density, crystalline structure, surface roughness, grain size, defects, porosity, etc. [6].

The requirement for diverse properties like optical, mechanical, and morphological provides bottlenecks for the industrial processing of transparent crowns. To get an idea about possible materials that may fulfil the above mentioned requirements, the Cambridge Engineering Selector [7] was applied and a short list of materials like Glass ceramic, Silica glass, Zirconia, Alumina, and Aluminium Nitride, etc. were made that seemed potential to provide the mentioned mechanical properties, surface roughness, and optical transparency. After a careful screening of the material properties, two materials were selected for the experiments. The first one was a natural feldspar veneering ceramic known as Vita VMK Master A3 (Vita) from Fiskars A/S, Denmark. The second material was Borosilicate -Boro 8330 (Boro) from Schott AG, Germany. Boro was used as both powder and finished glass. The main two constituents of the Boro material were $\mathrm{SiO}_{2}$ and $\mathrm{B}_{2} \mathrm{O}_{3}$. On the other hand, the two primary constituents for Vita were $\mathrm{KAlSi}_{3} \mathrm{O}_{8}$ and $\mathrm{NaAlSi}_{3} \mathrm{O}_{8}$. For the industrial production of the crowns two different process routes were selected for further investigations after the initial studies: i) Die pressing (compaction) and sintering; ii) Glass moulding.

\section{Experimental analysis, results, and discussion}

For the simplicity of the experiment, easier test, and comparison of materials, a simple circular shape (pill) with 10 $\mathrm{mm}$ diameter and $2 \mathrm{~mm}$ thickness was chosen as test geometry. The pills were made by mixing the powders with the binders and compressing in a hydraulic press. A careful consideration was made for the binder selection as it has a huge influence on the properties and toxicity of the final parts. The final choice as binder material was PolyproPylene Carbonate (PPC). This can make a complete and clean burnout at low temperatures. The raw binder was received as granulate and dissolved in Acetone before mixing with the ceramic powder. For the hardening, the green parts were heated to $180^{\circ} \mathrm{C}$ where the PPC was softened and bound to the other molecules. After cooling, the green part was hardened and became suitable for the next step. For forming the pills, a die pressing process was selected. The parts were compacted inside the die by a hydraulic press (Bench Top Manual Press from Carver with a maximum of $75 \mathrm{kN}$ pressing force). After the die pressing, the green parts were sintered to make them solid. The pressing tool, sintering oven, and the pills before and after sintering are shown in Fig 2. The sintering oven used was Programat CS Porcelain oven from Ivoclar Vivadent with a maximum firing temperature of $1200^{\circ} \mathrm{C}$. Sintering was performed in a vacuum condition to increase the densification and to prevent oxidation. The most important variables considered for sintering were: i) Heating rate, ii) Firing temperature (maximum sintering temperature), iii) Firing time, and, vi) Cooling rate. Initially, several trials and errors were performed to establish reasonable process windows for the sintering. Two different firing temperatures $\left(840{ }^{\circ} \mathrm{C}\right.$ and $\left.860{ }^{\circ} \mathrm{C}\right)$, three different firing times $(1.30 \mathrm{~min}, 4.00 \mathrm{~min}$, and $7.00 \mathrm{~min})$ with a heating rate of 30 ${ }^{\circ} \mathrm{C} / \mathrm{min}$, cooling rate $20{ }^{\circ} \mathrm{C} / \mathrm{min}$ were selected for investigation and further optimization. The sintered parts were characterized for shrinkage, surface roughness, porosity, hardness, and strength. The initial test showed that the mechanical strength requirements were fulfilled by both materials (both had Young's modulus > $50 \mathrm{GPa}$ and Compressive strength > $90 \mathrm{MPa}$ ). Both materials could fulfill the mentioned service temperature requirements. In this paper, focus is placed on the surface properties and the optical transparency of the material. The optimization of these two properties will be discussed in details.

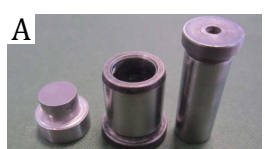

Pressing tool for pills

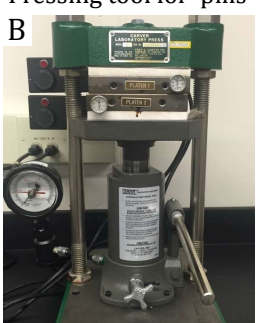

Hydraulic press
Oven used in experiments

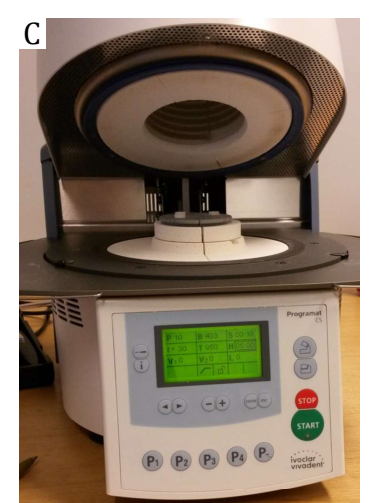

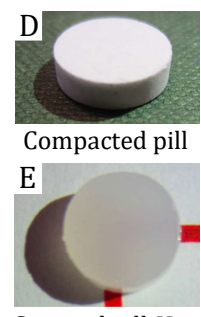

Sintered pill-Vita

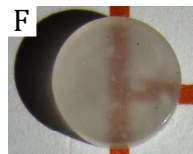

Sintered pill-Boro
Figure 2. Die pressing tool for the pills (A), hydraulic press (B) and the sintering oven (C) used in the experiments, pill after pressing and compaction (D), and the pills after sintering (E and F).

Surface analysis: The surface analysis was carried out with the help of an Alicona Infinite Focus Microscope and a commercially available software package for processing and analyzing microscopy images (Scanning Probe Image Processor version 6.6.1). The measurements were carried out with a magnification of 50x. As the samples were semi-transparent the Light Source was set to 0.45 and the Gain to 1.15 . The exposure was set to 2 and $3.5 \mathrm{~ms}$ (the higher the transparency the higher the exposure should be). The contrast was set to 0.3 . The vertical resolution used was $50 \mathrm{~nm}$. For every pill, 3 measurements around the point $(0,0),(2.5,2.5)$, and $(-2.5,-2.5)$ were made as shown in Fig 3-A. The scan area was $0.3 \times 0.3 \mathrm{~mm}^{2}$. 3D surface topography of two measurements in the middle $(0,0)$ of a Boro and Vita sample are shown in picture $B$ and $C$ respectively. The mean value was calculated for each of the samples and the measurement was repeated on 3 different samples to calculate the final average.

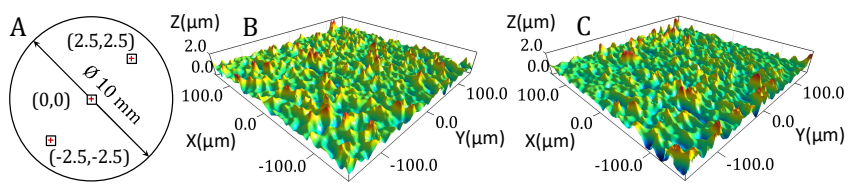

Figure 3. The positions for the surface roughness measurements (A), 3D surface pictures taken in position $(0,0)$ for Bora $(B)$ and Vita $(C)$.

The roughness analyses revealed the effects of the sintering parameters on the surface topography. The roughness was decreased with higher firing temperature and longer firing time for both the materials. The main effect plot and the timetemperature interaction of the Boro material are presented in plot A and B of Fig 4. The time-temperature interaction analysis showed that the influence of the firing time was decreasing at the high firing temperature and it was clear that the firing temperature was more influential for the surface roughness than the firing time within the experimental process window. A higher sintering temperature with lower sintering time could provide a similar effect as a lower sintering temperature and a higher sintering time for both the materials. This fact is important for the industrial optimization of the production as the production time can be reduced with increasing temperature. The roughness analysis showed that Boro obtained the lowest average surface roughness $\left(S_{a}\right) 332 \mathrm{~nm}$ (with $\sigma= \pm 29$ ), Vita had an average surface roughness $\left(\mathrm{S}_{\mathrm{a}}\right)$ of $549 \mathrm{~nm}$ (with $\sigma= \pm 76$ ). The porosity analysis (in three different locations in the middle sections of the sintered pills) showed that Vita had higher porosity (average $0.40 \%$ ) than the Boro material (average $0.05 \%$ ). The hardness measurement on the part surface showed the Vickers Hardness for both the 
materials was around $600 \mathrm{HV}$ which was fine for the dental application and the sintering conditions have little influence on the hardness of the parts. The low surface roughness and low porosity inside the parts made Boro a better material than the Vita. Moreover, the Boro pill showed better transparency compared to the Vita samples (as can be seen in Fig 2-F). But the transparency needed further optimization.

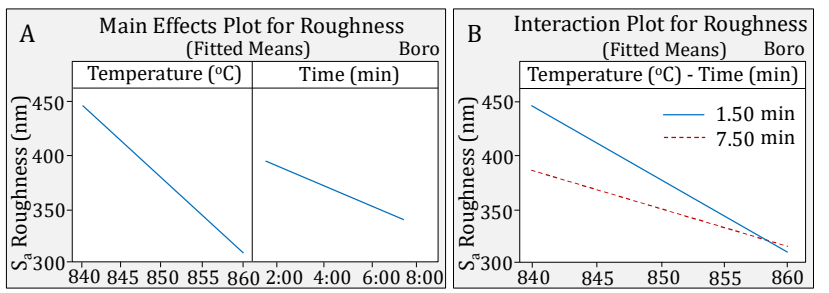

Figure 4. Main effect plot $(\mathrm{A})$ and interaction plot of surface roughness based on firing temperature and time for Boro material.

Transparency optimization: As the Boro material was found to be a better material in terms of surface roughness and porosity, the sintering condition for it was optimized to achieve the best possible transparency. Different combinations of the settings were tested. It was clear during the production of the samples that the high firing temperature increased the transparency of the samples, so the maximum temperature of the oven $\left(1200^{\circ} \mathrm{C}\right)$ was applied. The result was a highly transparent and melted item as shown in Fig 5-A. The viscosity became too low at $1200^{\circ} \mathrm{C}$ to let the item hold the shape. Fig 5-B shows some of the Boro samples sintered at different conditions. The sample S1 was sintered at $820{ }^{\circ} \mathrm{C}$ at a single firing temperature and as it can be seen in the picture, the part had low transparency.
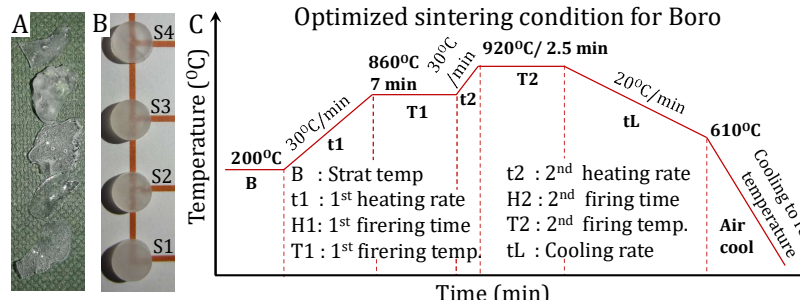

Time (min)

Figure 5. Melted Boro material at too high firing temperature (A), Boro pills sintered at different conditions (B), and optimized sintering process for Boro samples (C).

The reason for the low transparency of S1 was the too fast rise of the temperature when firing directly at $820{ }^{\circ} \mathrm{C}$. The fast temperature increase prevented a clear and complete phase transformation in the sample. The best transparency result was obtained (see sample S4 in Fig 5-B) where the parts were slowly heated from a start temp of $200{ }^{\circ} \mathrm{C}$ and two firing temperature $860{ }^{\circ} \mathrm{C}$ and $920^{\circ} \mathrm{C}$ were applied. The investigation showed that the cooling rate and cooling temperature were important too. The best results were obtained at a cooling temperature of $610{ }^{\circ} \mathrm{C}$ at a cooling rate of $20{ }^{\circ} \mathrm{C} / \mathrm{min}$. When decreasing the cooling temperature to $590{ }^{\circ} \mathrm{C}$ or increasing to $640{ }^{\circ} \mathrm{C}$ the transparency was decreasing (sample S2 and S3 respectively). A decrease in transparency was also noticed when the cooling rate was decreased to $10{ }^{\circ} \mathrm{C} / \mathrm{min}$ or increased to $40{ }^{\circ} \mathrm{C} / \mathrm{min}$. The knowledge gained from these experiments led to the optimized sintering condition (presented in diagram $\mathrm{C}$ of Fig 5) both for the transparency the surface roughness of the Boro parts.

\section{Production of the final crown}

For the prototyping of the crown, the first molar tooth of the lower jaw (tooth no 46 (as shown in Fig 1-A) denoted by the
Federation Dentaire Internationale Numbering System [8]) was chosen. The new crown was designed with a uniform thickness $(1.5 \mathrm{~mm})$ to avoid stresses in the material and to achieve a uniform toughness. The crown can provide a uniform load distribution which means that the crown can withstand a high load without any crack propagation. Capping the entire tooth is not necessary for the newly designed crown, meaning that the new crown can be placed with a minimal removal of the tooth and the large part of the original tooth can be retained. This is achieved by reducing the height of the crown. The design and dimensions of the prototype crown are shown in Fig 6.
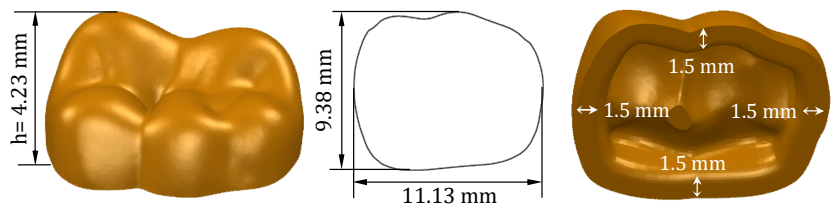

Figure 6. Design and dimensions of the molar tooth 46 for prototyping.

To produce the crown, first of all, the pills were formed following the process used in the previous experiment. This experiment was done only with the Boro as it imparted the best combination of the properties in the previous experiment. Afterward, these pills were pressed into the crown shape with the use of $\mathrm{Cu}$ mould coated with Ni (Fig 7-A). The formed crown can be seen in Fig 7-B. The next step was to debind and sinter the parts according to the optimized process develop in the previous experiments. The final result showed a worse transparency of the formed crown compared with the pills (Fig 7-C).
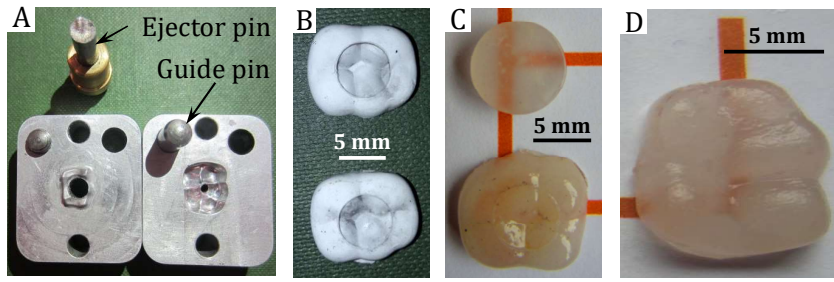

Figure 7: The tool (A) and the formed crown (B), sintered crown compared with the sintered pill (C), final crown after polishing (D).

It revealed a significant effect of the part geometry on the transparency of the material. The sintered crown was polished with a hand-held nano polisher to remove the ejector mark and debris from the surface. Polishing is commonly applied whenever defect-free surfaces with a low roughness are required [8]. After polishing, the parts were cleaned with Acetone in an ultrasound cleaner for $20 \mathrm{~min}$. The results can be seen in Fig 7-D. This crown was not suitable for the light curing of the dental glue due to the low transparency. But its milky white color was close to the natural color of human teeth. Meaning, it can be used with other types of dental glue that are not cured by light (e.g. the twocomponent dental glue). This can provide a cheaper alternative compromising the aesthetics for the cost of molar and pre-molar teeth when they are less visible compared to the other teeth. To obtain a better transparency from the Boro crowns, another process based on glass moulding was developed and optimized.

Glass moulding for the dental crown: Glass moulding is a compression based replicative process that allows the production of high precision optical components with surfaces finish even in the range of few nanometres [10]. The advantage of the glass moulding for the current application compared to the compaction and sintering based process is that the material is already transparent and only one process step is needed to produce the crown. The process was executed with Borosilicate glass sheet 
with a thickness of $2.6 \mathrm{~mm}$. Pieces with the rough profile of the crown were cut with a water-jet cutter out of the sheet (as shown in Fig 8-A). The glass moulding requires a heat-resistant mould. So a Tungsten (W) mould was designed and produced (shown in Fig 8-B) for this purpose by sinking EDM. The glass piece after the jet-cut was placed in the mould cavity and the mould was closed and locked with a locking mechanism (shown in Fig 8-C). Before this process was carried out, the temperature and time where the Borosilicate was soft enough for reshaping were determined. The most optimal option was to heat the material to $880{ }^{\circ} \mathrm{C}-920^{\circ} \mathrm{C}$ for 1.5 to $2 \mathrm{~min}$. Vacuum was used to avoid burning and air inclusion. A mould release agent (Boron Nitride Aerosol Lubricoat from Zyp Coatings Inc., USA) was chosen to get the parts easily out from the mould. After heating the closed mould, it was pressed with a pressing force of $40 \mathrm{kN}$ with the hydraulic press. The cooling was important to achieve the right mechanical properties of the crown. The optimized cooling method in the previous experiment (cooling to $610{ }^{\circ} \mathrm{C}$ with the rate of 20 ${ }^{\circ} \mathrm{C} / \mathrm{min}$ before letting the air cool down the part to the room temperature) was used. The parts made by the glass moulding were not $100 \%$ transparent either, but they were much better compared with the previous samples (shown in Fig 8-D).
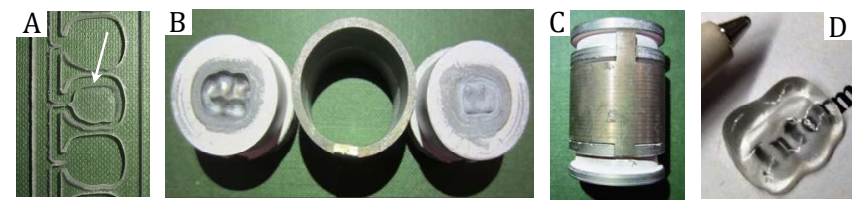

Figure 8. Picture showing a piece cutout from the Boro glass sheet with the rough profile of the tooth (A), W tool components (B), assembled tool with the locking mechanism (C), a glass moulded crown (D).

Functional testing of the crown: The last part of the work was to test the bonding and hardening of the glue with the transparent crown and to evaluate the color matching. The crown made by glass moulding was assembled to a demonstrator tooth by a dental glue known as Kerr OptiBond from Kerr Dental, USA. The glue was successfully hardened by UV light passing through the crown. The curing time was 45 seconds. After curing, the color of the glue was visible through the transparent crown and that could make the color matching for the tooth. The prototype tooth can be seen in Fig 9-A and the comparative color matching with a color-coded tooth is shown in Fig 9-B. The bond strength of the glue and Boro crown were evaluated by tensile testing. 5 test results from 5 different samples are presented in Fig 9-C. The tensile force was higher than $400 \mathrm{~N}$ in all cases. This means that the bond strength was higher than the mouth opening force of an adult human (approximately $241 \mathrm{~N}$ [11]), thus meets the requirement for the dental application.
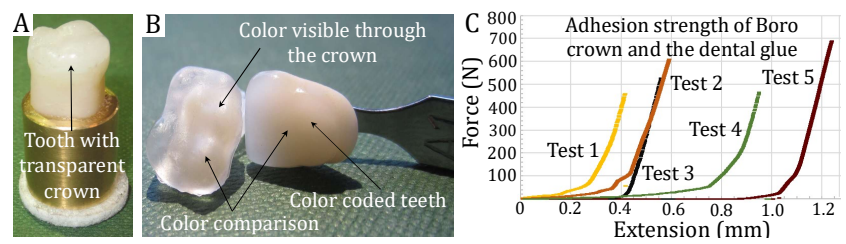

Figure 9. Demonstrator tooth made from Boro crown (A), comparison of color matching (B) and bonding force of the crown and dental glue (C).

\section{Summary and conclusion}

This paper presents the idea and manufacturing possibilities of mass-produced dental crowns for molar and pre-molar teeth. The benefit of this work will be realized all over the world especially in low-income countries. The new crown concept provides a faster, cheaper and flexible solution to the patients needing a dental crown. The first set of experiments conducted in this work proved that the test samples (pills) and the crowns sintered at the same conditions were not the same in transparency proving the effect of the part geometry on the transparency. The analyses showed that the longer sintering time decreased the average surface roughness but the influence of the firing time was decreasing at higher temperatures. The change in the firing temperature had a relatively higher influence on the surface roughness than a change in the firing time. A milky white crown was achieved as end result by the sintering process with Boro which can be a cheap alternative for the patients who do not care much about the aesthetics of the inner teeth. The glass moulding process was developed and optimized to achieve better transparency. The glass moulded crowns were good enough for the light hardening of the dental glue. Future work should focus on the investigation of the sub-surface damage (fractured and stressed material under an apparently defect-free surface [12]) in the transparent crowns. A quantitative analysis for the optical transparency of the moulded crowns should be performed. Another interesting research to be carried out is to develop a process to achieve variable hardness over the crown surface to simulate the precise functionalities of natural human teeth.

\section{References}

[1] Makhija, S.,K., Lawson, N., C., Gilbert, G., H., Litaker, M., S., et. al., 2016, Dentist Material Selection for Single-Unit Crowns: Findings from The National Dental Practice-Based Research Network, Journal of Dentistry, 55:40-47.

[2] Bell, A., M., Kurzeja, R., Gamberg, M., G., 1985, Ceramometal crowns and bridges. Focus on failures, Dent Clin North Am, 29(4):763-78.

[3] Ramsden, J., J., Allen, D., M., Stephenson, D., J., Alcock, J., R., Peggs, G., N., Fuller, G., Goch, G., 2007, The Design and Manufacture of Biomedical Surfaces, CIRP AnnalsManufacturing Technology, 56 (2): 687-711.

[4] Kong, L., B., Huang, Y., Z., Que, W., X., Zhang, T., S., et. al., 2015, Transparent Ceramics, Springer International Publishing Switzerland, ISBN 978-3-319-18956-7.

[5] Chun, D., M., Davaasuren, G., Ngo, C., V., Kim, C., S., Lee, G., Y., Ahn, S., H., 2014, Fabrication of transparent superhydrophobic surface on thermoplastic polymer using laser beam machining and compression molding for mass production, CIRP Annals-Manufacturing Technology, 63: 525-528.

[6] Cho, M., S., Lee, Y., K., Lim, B., S., Lim, Y., J., 2006, Changes in optical properties of enamel porcelain after repeated external staining, J Prosthet Dent., 95(6):437-43. [7] The Cambridge Engineering Selector, CES EduPack 2017, User Manual and Getting Started Guide, Version: CES-E17.01, March 2017, Granta Design Limited, UK. [8] Justi Educational Department, 2010, Dental Numbering Systems - Rev. 9/03.

[9] Klocke, F., Zunke, R., 2009, Removal mechanisms in polishing of silicon based advanced ceramics, CIRP Annals-Manufacturing Technology, 58: 491-494.

[10] Hansen, H., N., Hocken, R., J., Tosello, G., 2011, Replication of micro and nano surface geometries, CIRP Annals - Manufacturing Technology, 60:695-714.

[11] Chandran, R., 2012, Poster 100: Measurement of the Isometric Mouth Opening Forces in an ASA I, 20-40-Year-Old Patient Population, Journal of Oral And Maxillofacial Surgey, 70 ( 9 supplement -2):e103.

[12] Williams, W., Mullany, B., Parker, W., Moyer, P., Randles, M., 2010, Using quantum dots to evaluate subsurface damage depths and formation mechanisms in glass; CIRP Annals - Manufacturing Technology, 59: 569-572. 